Sergey M. Burkov¹, Igor P. Loginov², Sergey Z. Savin～DOI: 10.24057/2414-9179-2018-1-24-194-201

\title{
GEOINFORMATION SYSTEM FOR ANALYSIS OF ETHNO-CRIMINOLOGICAL SITUATION IN PRIAMURYE
}

\begin{abstract}
Growth of narcological disease, its distribution in regions of the moderate and low risk, preclinical diagnostics and methods of revealing of contingents of risk of a drug addiction staticize the big moral and economic losses connected with treatment and social protection of patients, inevitable direct and indirect losses of productive forces, absence of accessible methods interdisciplinarity researches. Are spent socially-psychological, narcologo-epidemiological, ethnocultural, criminological and medicogenetic researches of features of distribution of chemical dependences in territory of Amur region of Khabarovsk territory. Despite certain successes in business of preventive maintenance, early diagnostics and treatment of narcotisms, the problem of distribution of psychoactive substance remains to one of the major for medicine, criminology, sociology, psychology and economy of Far East federal district. Methods of studying of behavioural reactions of persons inclined to dependent behaviour, medico-genetic methods, psychologosociological methods, methodology ethnocultural and transcultural analysis, methods of information modelling with application of new information technology are used psychometric and sociometric. Results of GIS-researches will allow to improve structure of the psychological and narcological help to the region population, development of effectual measures of social protection, preventive maintenance and a mental health care of the population of Amur region.
\end{abstract}

KEYWORDS: geoinformation system (GIS), socially significant disease, epidemiology, psychoactive substances (PS), social psychiatry.

\section{INTRODUCTION}

Narcotism and alcoholism is the inconsistent and most dangerous phenomena in life of a modern society. Comprehension of this tragical danger forces to analysis attentively results of the measures accepted for struggle against the given phenomenon. Drugs is the one of those problems which probably to solve only at mankind level as a whole (United Nations Office for Drug Control and Crime Prevention. Drug abuse rapid situation assessments and responses. Vienna, March 1999. 47 p. https://unstats.un.org/home; accessed 11.04.2018). Drugs is deadly threat to present and future generation of people. Drugs deform the person of the person, not without reason the most brutal crimes are made by the people drugged by a drug. At the addict in so-called "withdrawal" there is an insuperable requirement for drugs contrary to everything, is frequent it much more strongly, than abstinence syndrome at the alcoholic [Sourse book..., 1996]. In such situation there is a fixing of all spheres of the person (physical, psychophysiological, psychological and socially-psychological) on satisfaction of such requirement. If to analysis those crimes which are made because of a narcotism and alcoholism their considerable part is caused at all by aspiration to extract money for a dope, and by a consequence of the most narcotic or alcoholic intoxication (About the state sanitary and epidemiological wellbeing of the population in the Russian Federation in 2013: survey report. M.: The Federal service for supervision of consumer rights protection and human well-being, 2014. 191.). Initial process of

\footnotetext{
${ }^{1}$ Pacific National University, Tihookeanskaya str., 136, 680035, Khabarovsk, Russia,e-mail: c_burkov@mail.ru

2 The Far Eastern State Medical University, Muravyov-Amursky str., 35, 680000, Khabarovsk, Russia, e-mail: log-i-p1954@mail.ru

${ }^{3}$ Pacific National University, Tihookeanskaya str., 136, 680035, Khabarovsk, Russia, e-mail: savin.sergei@mail.ru
} 
the use of drugs creates such proof neurophysiological and psychological changes in a human body that treatment of addicts turns in very expensive and labour-intensive process. The use of drugs by men and women in the genital period of life leads to occurrence of children already having irreversible changes in a brain. Narcotism - process self-induced, itself regenerating. Communication with definitely life and sources of reception of drugs is often traced. The narcotism in many senses is immoral, since freedom of one person should not enter into the contradiction with the elementary rights of others [Bobak et al., 1998]. The use of drugs is one of symptoms of various neurotic conditions [Sourse book..., 1996; Hibell et al., 1998]. Drugs in an interlacing of various neurotic conditions transform all addicts into psychological copies of the person each other. The use of drugs is only a consequence, instead of the reason. If to treat only a consequence, without having cleaned the reason leading to a narcotism such treatment of success has no [Hofman et al., 2010; Loginov et al., 2015]. Dependence between abusing narcotic substances on the one hand and social, psychological, genetic and biochemical characteristics of patients [Sourse book..., 1996; Hibell et al., 1997] is authentically studied. It is possible to list in decreasing order the most important signs, being factors of development of a narcotism: alcoholization of one or both parents; neglect; low general educational level of a family; high level of a conflictness in a family and disputed character of mutual relations with associates; an incomplete family; low authority of parents and, especially, the father; biologically changed constitution of an organism (characterologic anomalies, psychopathysation, brainorganic insufficiency and so forth). In narcotism and alcoholism distribution far not last role is played also by social factors [Bobak et al., 1998; Mostovoy, Mihaylov, 1999]. Clearly that so difficult phenomenon cannot be investigated within the limits of one scientific discipline, methods of the system analysis and the interdisciplinary approach therefore are so important and actual. The purpose of our researches is working out on the basis of the system analysis of practical recommendations for employees of bodies of public health services, social protection and the law and order on diagnostics, the differentiated estimation of frustration of the person at alcoholism and a narcotism, to the differentiated choice of means of treatment and rehabilitation of patients and preventive maintenance of chemical dependences in territory of Amur region of Khabarovsk territory.

\section{MATERIALS AND METHODS}

As research material 60 men at the age from 26 till 50 years with the diagnosis "alcoholic dependence" by criteria ICD-10, Amur region constantly living in territory and not connected among themselves relationship bonds have served. Control sample is generated from almost healthy 60 men of the same age group which are not consisting on the account at the psychiatrist or the expert in narcology and denying by results of structured interview and the retrospective analysis the facts of abusing of PS. At selection of a clinical material it was found out also hereditary burdeness, the transferred illnesses and traumas, features of previous development and character and person formation, vital events, interests and habits. Research does not join patients at which alcoholism is combined with other mental diseases, 3rd stages sick of alcoholism sick of alcoholism at which abusing alcohol was combined with regular reception of other psychoactive substances, with presence premorbid pathologies of the person, consequences of organic defeats of a brain and accompanying somatic diseases, and also patients aged are younger 26 and is more senior 50 years. Influence of these factors is important for excluding to find out a role actually alcoholisation in occurrence and development of the specified kinds of frustration of the person. As a result 30 persons with authentic signs of the alcoholic dependence which have reached of a stage of full development of illness without obvious participation additional diseases and pathoplastic of factors have been selected. 
For ethno-ecological researches we had been used methods of psychological anthropology (PA). The PA includes a trans and crosscultural researches in the field of psychiatry and narcology, is based on multidisciplinary researches and concerns to integrative to the sciences studying the person in all forms. The basis of narco-psychiatric symptoms is covered in three main reasons: social, psychological and individually-biological. Relative density and the importance of a making triad conditional are connected with features of population in which conditions there is a formation of clinical psychotype [Hibell et al., 1997; Hofman et al., 2010]. For the correct analysis, interpretation and gathering socially-psychological and ethnocultural given we had been created special questionnaires. For a basis of methodological principles of drawing up of psychodiagnostic questionnaires were the ideology of tests of Leary, Lusher, UCLA, MMPI and also means of questioning earlier developed by us in groups of the narcological risk, added with questions on features of group behaviour is used. Along with it the approved methods of sociometria, social psychiatry, social psychology (interview, tests, supervision, questionnaires and so forth) have been used Psychodiagnostics, psychological anthropology (PA). From positions of the PA the ethnopsychiatry and ethnonarcology can be studied integrative as multidimensional GIS-space of versatile signs. Thus the basis of psychiatric symptoms is covered in the social, psychological and individually-biological reasons. Relative density and the importance of making this triad conditional are connected with features of population in which conditions there is a formation of clinical behavioural psychotype. Dependent or addictive the behaviour (DB) is characterised by aspiration to leaving from a reality by means of change of the mental condition. If the person lives in conditions addictive systems, it becomes fractal the carrier of characteristics of this system that imposes on its person and the subsequent life a serious print.

Thus as material substratum DB not necessarily serves what either a physical body or chemical substance. But chemical dependences give to the person somewhat unique experience of perception of a reality at the expense of perception "shift" in touch channels which is perceived in the form of unusual visual images, sounds, corporal sensations. Familiarising with new "positive" experience and residing causes it dependence on the experience. In this case the chemical substance is only the stimulus starting possibility of connection with new experience. Thus, it is possible to allocate classes and stimulus of not chemical influence for perception of a reality. At society level probably use synergetic approaches of researches, and at level of group behaviour is the most effective application of methods of theoretic-game modeling of disputed systems [Barabash et al., 2005; Loginov et al., 2015]. By us have been used psychometric and sociometric methods of studying of behavioural reactions (screening-poll, interview, testing, game, interaction), medical methods (poll, natural supervision, catamnesis, epidemiological research), sociological methods (studying of medical and social activity of patients in the course of interview), methodology ethnocultural and transcultural the analysis, methods of information modelling, medico-ecological geoinformation systems (MEGIS) [Barabash et al., 2005; Bolstad, 2005; Kosykh et al., 2008]. Besides the narcoepidemiological, sociological, demographic, criminal statistics and the data of social and ecological intensity as thematic layers GIS data [Heywood et al., 2006; Harvey, 2008; Burrough et al., 2015; Kaganovich et al., 2018] on distribution of PS, narcological disease, and also macroeconomic and socially-demographic parameters (natural increase and decline in population indicators, population employment, age-gender structure, a migration index, a crime rate, a turn of PS and so forth) [Fedorov, Romanov, 1999; Kosykh et al., 2008; Platonov, 2012].

\section{RESULTS}

Our interdisciplinary researches testify to presence of close interrelation between various ethnic and sociocultural characteristics, clinical structure and dynamics of variety of mental frustration and is criminal-addictive behaviour among the population of the 
Far East of Russia. The analysis of the statistical data testifies to steady involving of the population in processes of narcotization, decrease in age of familiarising with psychoactive substances, spectrum expansion narcotically the operating substances which are accessible to consumer. In spite of the fact that currently number narcodependent, being on the account in edge narcoclinics while essentially concedes to cases of chronic alcoholism, the tendency of growth of number of patients with given nosology should cause fears. At multidisciplinary researches of a narcological situation in edge we have faced a number of methodological problems. For reception of an objective picture of narcodisease as rather an unusual occurrence for the small population non-uniformly distributed on the extensive area, as a rule, corresponding research resources, auxiliary forces and a considerable cost of transportation [Barabash et al., 2005] are required.

Specificity in this business is introduced by national and social and economic distinctions of the population, non-uniformity and heterogeneity of a communication and transport network. 20-year-old forwarding experience in lower reaches of the Cupid, including territories of compact residing of the radical (native) population, allows to give some rough estimate of narcological conditions without carrying out of special psychosocial of medical examination which is based on the indirect information from sources which can be trusted. Researches from positions of the system analysis have allowed to estimate the contribution of psychiatric illnesses to the capital of mental health of region. In the course of GIS-researches within the limits we had been created methodology of an estimation of losses from this kind of psychiatric diseases in Khabarovsk territory (straight lines, indirect, public, social, economic), definitions of critical zones of growth of losses, working out of a technique of an integrated estimation of psychiatric losses, calculation of expected losses on individual and population level, at various stages of the basic forms of dependences is carried out.

The psychopathology, clinical pathomorphosis alcoholism at the radical people has been studied, dynamics of development of dependences, psychotherapeutic approaches to treatment and rehabilitation of consumers of psychoactive substances are planned. The beginning of the incidental use of hashish at small nationalities is necessary on age of 7-9 years, at Russian 10-12 years. The age of the beginning of the regular use of hashish at small nationalities has made 10-10,5 years - in countryside and 12-14, years - in cities, among Russian - 12-14 years. It speaks easy availability and an abundance of growing hemp in countryside. Hashish use not only for smoking, but also add in tea during meal. Studying of genealogical characteristics at drug patients among indigenous people has shown high figures hereditary burdeness at $28,9 \%$ of patients one of parents suffered alcoholism and incidentally used hashish, 16,3\% of cases fathers suffered hashish a narcotism and passed treatment together with the children, in $4,6 \%$ of cases one of parents suffered a schizophrenia, in 28,0 \% - intellectual backwardness, in $5,9 \%$ - an epilepsy. Causes alarm that in 50,4 \% of parental families in group of small nationalities the relation to the use of drugs positive, and in $26,7 \%$ - indifferent.

In group of Russian active counteraction was rendered by almost all parents. In group of the small nationalities living in countryside, at $20,3 \%$ of patients the condition narcotic intoxication was estimated as depressive, at $8,1 \%$ of patients - with elements explosivity, at $29,2 \%$ of patients euphoria with silliness prevailed, at $30,1 \%$ of patients the condition was characterised as wavy with change depressive, explosive and euphoric conditions. As a rule, the arising condition of depression passed in some minutes in euphoria with silliness, on the contrary, the euphoria condition passed in a depression condition. The reasons somatoform frustration and neurologic characteristics at teenagers, consumers of PS, psychophysiological features and the somatic frustration influencing on deviant behaviour, a spectrum somatoform frustration, correlation with level of the conflict, an adaptation and 
training problem, communication somatoform frustration and teenage aggression, degree somatoform and behavioural frustration at victims of physical and mental violence were analysed [Barabash et al., 2005].

According to our GIS-researches, relations to ceremonial activity at modern natives of Amur region it is far not unequivocal [Loginov et al., 2015]. If to take only one aspect ethnocultural conditions, namely activity performance as that distribution looks so: follow, as a rule, to various forms of ceremonial activity $-23 \%$; follow sometimes $-46 \%$; do not follow $-31 \%$. With high degree of reliability it is established that activity of following cultural to activity promotes preservation of personal structure and social adaptation in ethnocultural to environment, but does not prevent from development of more and more malignant psychopathological variant of a current of alcoholism. Leaving from performance ethnocultural activity considerably complicates social adaptation in a circle of the ethnos, but forms optimum - a somatopathological variant of alcoholic dependence is more often. So, ethnobiological level cultural influences on an alcoholism current has not direct concrete answers, and is mediated through a difficult complex of biosocial adaptable mechanisms [Mostovoy, Mihaylov, 1999]. Multifactorial clustered the analysis has allowed to unite groups of administrative areas of Khabarovsk territory similar among themselves on a number of parametres, in so-called medico-ecological zones (see cards-schemes on Fig. 1). In these zones (Fig. 1) was spent rank the analysis (the above a rank, the more darkly zone colouring) abusings of PS against some forms of accompanying lethal and not lethal diseases (psychiatric, immuno-scarce, demyelination), criminogenic situations and etc. [Barabash et al., 2005; Kosykh et al., 2008].

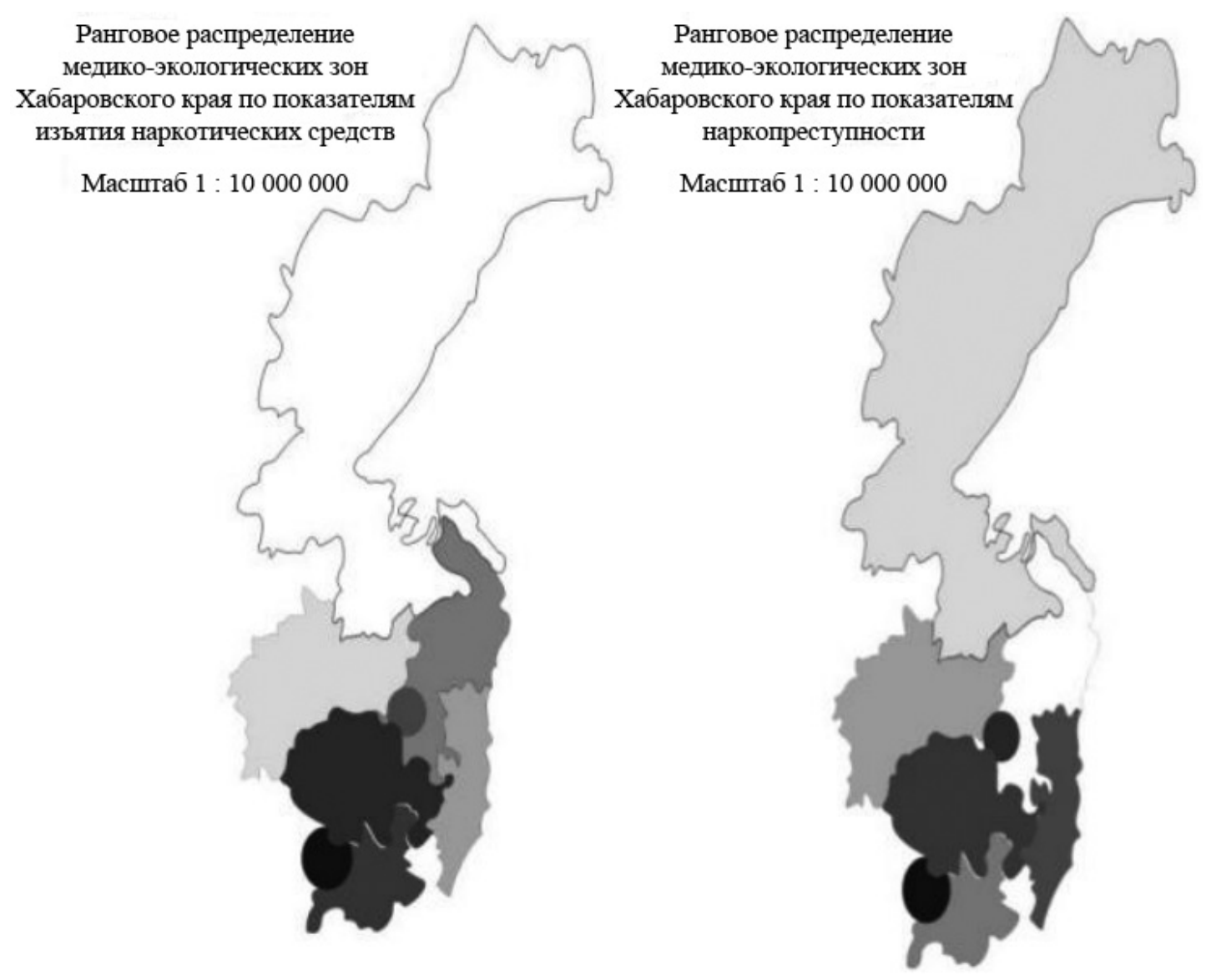

Fig. 1. Rank indicators of a narcological situation in Khabarovsk territory 


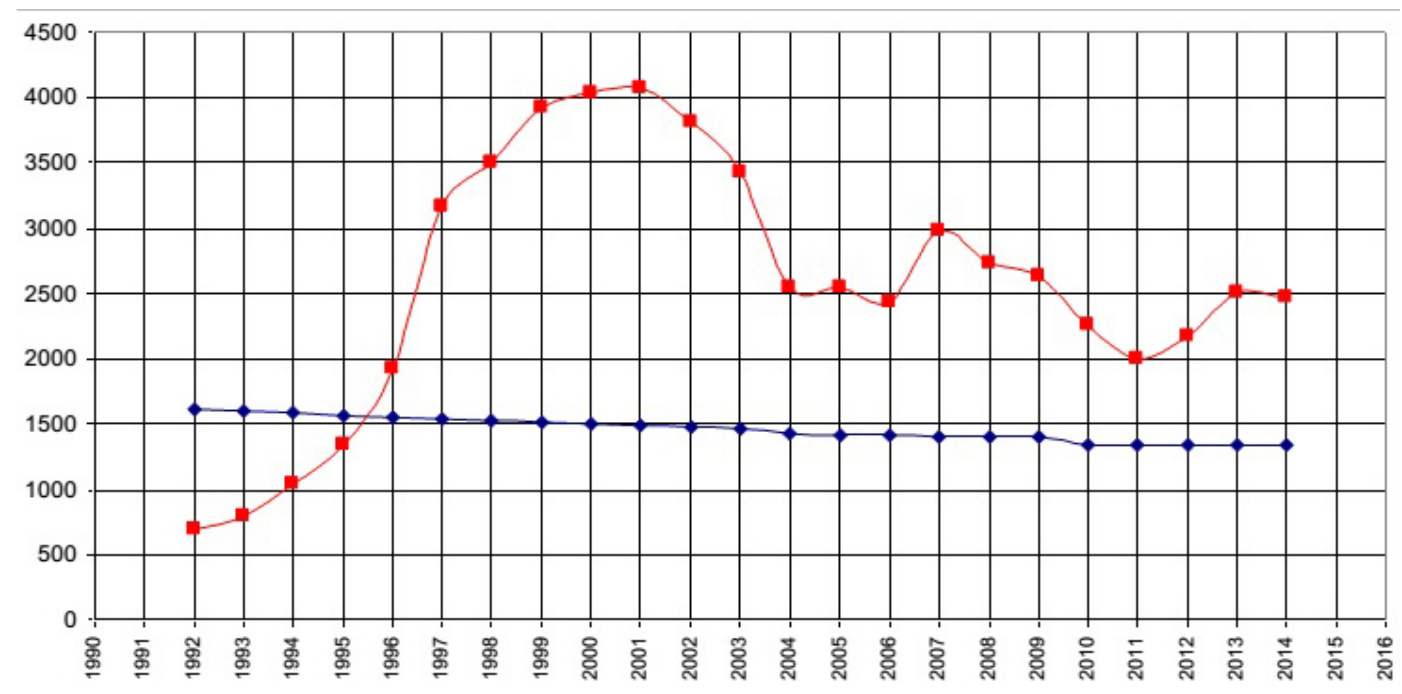

Fig. 2. Quantity of crimes on a drug trafficking

- population of Khabarovsk territory in hundred peoples

- quality of crimes on a drug trafficking

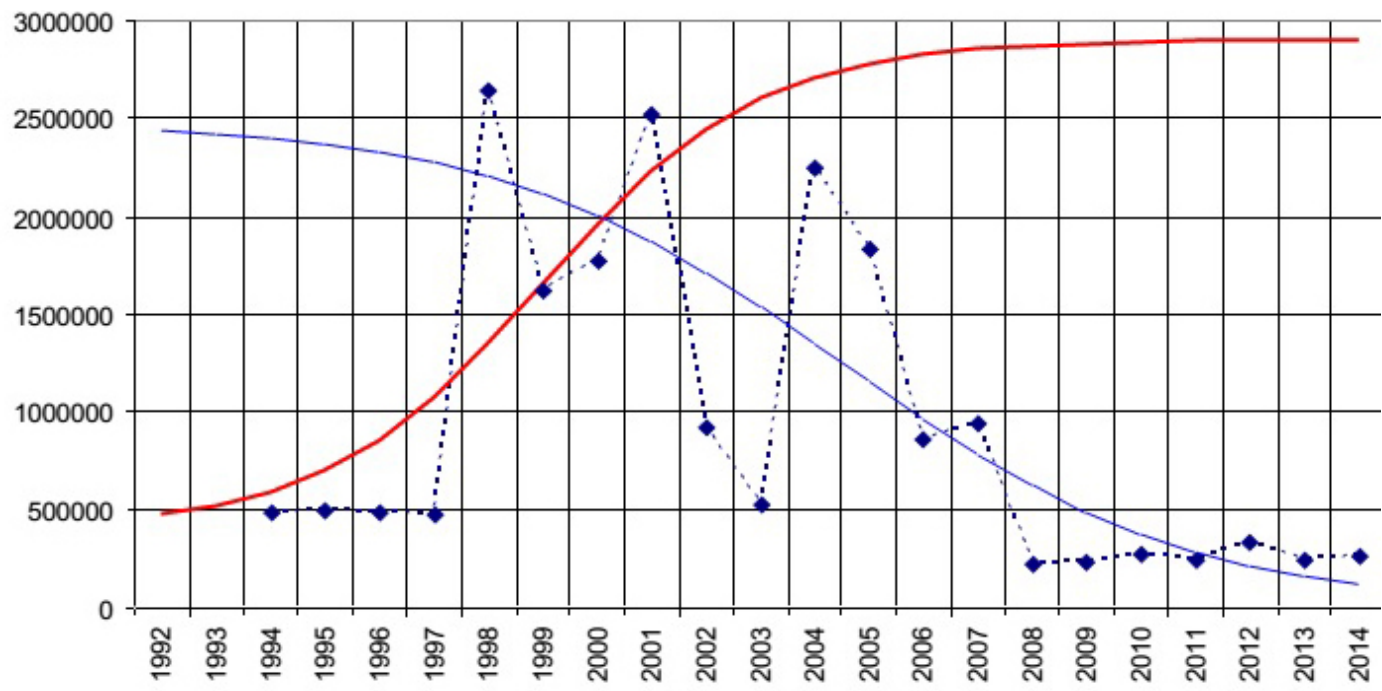

Fig. 3. It is withdrawn drugs

- withdrawn drugs in gramm

- model 1

- model 2

Fig. 2-3 reflect the cores social and economic and criminogenic factors of distribution of PS.

The Fig. 2 illustrates the data about number of the crimes connected with a drug trafficking in Khabarovsk territory from 1990 for 2014 in comparison to dynamics of population of edge for the same period. From this data direct communication between population and quantity of similar crimes is not seen. This fact can be interpreted in such a manner that medical and biologic factors are not defining, at least, in criminality sphere. Much bigger value data on superprofit from illegal activity on spread of drug addiction and variable have activity of law enforcement bodies in struggle against this phenomenon [Barabash et al., 2005]. As an example we will consider indicators of withdrawal of drugs 
in the course of struggle against the criminality, presented on Fig. 3. It is possible to notice that after especially successful actions and withdrawal of large parties of narcotic substances within 2-3th years in region level of drug trafficking and, accordingly, quantity of the withdrawn drugs) sharply falls - model 1. Even if drug dealers for this period find ways to restore delivery of narcotic substances, the total turnover of drugs decreases - model 2. From the resulted data it is visible that for last decade it was possible to lower and stabilise some a crime rate in Khabarovsk territory, connected with drugs.

\section{CONCLUSIONS}

Steady universal growth of narcological disease, its distribution in regions of the moderate and low risk, preclinical diagnostics and methods of revealing of contingents of risk of a drug addiction staticize the big moral and economic losses connected with treatment and social protection of patients, inevitable direct and indirect losses of productive forces, absence of accessible methods interdisciplinarity researches by geoinformation system.

A theoretical basis of workings out is the social psychiatry, ethnocultural and transcultural methods, the system analysis and mathematical modelling with application of methods of social psychology, the device of the theory of games and geoinformatics for processing of the versatile information at decision-making on optimization of structure of the psychological and narcological help.

For the first time the narcological situation in Khabarovsk territory is investigated in socially-psychological aspect with attraction of related subjects: psychiatry, ecology, economy, mathematics, computer science, cultural science, ethnography, political science, conflictology.

The GIS-analysis of distribution of a group drug addiction has allowed to reveal sociallypsychological, ethno-narcological and medico-ecological features of region.

Having defined the main reasons predetermining a meeting of the person from PS, it is possible to define and effective tactics of search of an exit from a state of dependence as begins possible to represent and algorithm of occurrence and narcotism and alcoholism development, and versatile risks.

\section{REFERENCES}

1. Barabash P.I., Posvalyuk N.E., Savin S.Z., Motrich E.L., Shamov V.V. Using of geoinformation systems for narcological-demography monitoring of the Far East. Research in Russia. 2005. No 1. P. 740-752 [e-journal]. URL: http://zhurnal.ape.relarn.ru/articles / 2005/068.pdf. 068/041212, (accessed 10.04.2018) (in Russian).

2. Bobak M., Pikhart H., Hertzman C. Socioeconomic factors, perceived control and selfreported health in Russia. A cross-sectional survey. Soc Sci Med 1998; 47: 269-279.

3. Bolstad P. GIS Fundamentals: A first text on Geographic Information Systems, Second Edition. White Bear Lake, MN: Eider Press, 2005. 543 p.

4. Burrough P.A., McDonn R.A., Lloyd C.D. Principles of Geographical Information Systems (Spatial Information Systems). New York: Oxford University Press, Third Edition. 2015. 432 p.

5. Fedorov M.P., Romanov M.F. Mathematical basics of ecology. SPb.: SPbGTU Publishing, 1999. 156 p. (in Russian).

6. Harvey F.A. Primer of GIS, Fundamental geographic and cartographic concepts. The Guilford Press, 2008. 31 p.

7. Heywood I., Cornelius S., Carver S. An Introduction to Geographical Information Systems. 3rd edition. Prentice Hall. 2006. 446 p. 
8. Hibell B., Andersson B., Bjarnson T., Kokkevi A., Morgan M., Narusk A. The 1995 ESPAD report. The European School Survey on Alcohol and Drugs. Alcohol and Other Drug Use Among Students in 26 European Countries. Stockholm, 1997. 294 p.

9. Hofman A.G., Kojinova T.A., Yashkina I.V. About alcohol situation in Russia and ways of optimization of antinarcological service // Independent psychiatry journal. 2010. No 2. P. 11-13. 10. Kaganovich A.A., Prisiazhniuk S.P., Prisiazhniuk A.S., Karmanov A.G. Geoinformation technologies in questions of spatial development // Disasters. 2018. V. 46, No 2. P. 352-364 (in Russian).

11. Kosykh N.E., Lopatin A.S., Novikova O.Yu., Savin S.Z. Geoinformation systems in medical ecology problems. Vladivostok: Dalnauka, 2008. 153 p. (in Russian).

12. Loginov I.P., Solodkaya E.V., Savin S.Z., Congpei Zhang, Xigin Van, Liu Yulya, Yu Fenguy. Transborder researches of the situation with mental health among teenagers // Far Eastern medical journal. 2015. No 1. P. 37-40 (in Russian).

13. Mostovoy S.M., Mihaylov V.I. Ethnocultural particularities of spread of alcoholism and alcohol psychoses in Khabarovsk krai. Khabarovsk: HKCPH, 1999. 54 p. (in Russian).

14. Platonov Yu.P. Ethnopsychology. M.: Academy Publ., 2012. 240 p. (in Russian).

15. Sourse book of substance abuse and addiction narcology. Friedman L.S., Fleming N.F., Robers D.H., Hyman S.E. (Ed.). Williams and Wilkins, 1996. 352 p. 